\title{
Parameter Studies on High-Velocity Oxy-Fuel Spraying of CoNiCrAlY Coatings Used in the Aeronautical Industry
}

\author{
J. A. Cabral-Miramontes, ${ }^{1}$ C. Gaona-Tiburcio, ${ }^{1}$ F. Almeraya-Calderón, ${ }^{1}$ \\ F. H. Estupiñan-Lopez, ${ }^{1}$ G. K. Pedraza-Basulto, ${ }^{1}$ and C. A. Poblano-Salas ${ }^{2}$ \\ ${ }^{1}$ Facultad de Ingeniería Mecánica y Eléctrica (FIME), Centro de Investigación e Innovación en Ingeniería Aeronáutica (CIIIA), \\ Universidad Autónoma de Nuevo León (UANL), Aeropuerto Internacional del Norte, Carr. Salinas Victoria Km. 2.3, \\ 66600 Apodaca, NL, Mexico \\ ${ }^{2}$ Centro de Tecnología Avanzada (CIATEQ, A.C.), Procesos de Manufactura, Avenida Manantiales 23-A, \\ Parque Industrial Bernardo Quintana, 76246 El Marqués, Qro, Mexico
}

Correspondence should be addressed to J. A. Cabral-Miramontes; jocamira@hotmail.com

Received 18 October 2013; Accepted 11 January 2014; Published 6 March 2014

Academic Editor: Patricia Zambrano

Copyright (๑) 2014 J. A. Cabral-Miramontes et al. This is an open access article distributed under the Creative Commons Attribution License, which permits unrestricted use, distribution, and reproduction in any medium, provided the original work is properly cited.

The thermal spraying process is a surface treatment which does not adversely affect the base metal on which it is performed. The coatings obtained by HVOF thermal spray are employed in aeronautics, aerospace, and power generation industries. Alloys and coatings designed to resist oxidizing environments at high temperatures should be able to develop a surface oxide layer, which is thermodynamically stable, slowly growing, and adherent. MCrAlY type ( $\mathrm{M}=\mathrm{Co}, \mathrm{Ni}$ or combination of both) coatings are used in wear and corrosion applications but also provide protection against high temperature oxidation and corrosion attack in molten salts. In this investigation, CoNiCrAlY coatings were produced employing a HVOF DJH 2700 gun. The work presented here focuses on the influences of process parameters of a gas-drive HVOF system on the microstructure, adherence, wear, and oxygen content of CoNiCrAlY. The results showed that spray distance significantly affects the properties of CoNiCrAlY coatings.

\section{Introduction}

Thermal barrier coatings (TBC) are widely used to increase the efficiency and protection of metallic components that suffer degradation due to corrosion, oxidation, or excessive heat load during service in thermally drastic environments. Some of its main applications are on gas turbines engines and also in aerospace and aircraft applications $[1,2]$. The most common TBC-systems consist of a nickel-base super alloy as substrate, a MCrAlY layer ( $\mathrm{M}: \mathrm{Ni}, \mathrm{Co}, \mathrm{Fe}$, or combination of these elements) as bond coat. MCrAlYs are one of the most important protective coating materials applied to gas turbine parts [3,4]. MCrAlY coatings protect the components against high temperature oxidation and hot corrosion attack, typically deposited by Vacuum Plasma Spray (VPS) or LowPressure Plasma Spray (LPPS), by Air Plasma Spray (APS), and recently by High Velocity Oxy-Fuel process (HVOF).
However, the HVOF thermal spray is a highly cost effective method to add properties and performance qualities over these surfaces. MCrAlY systems provide some benefits of $\mathrm{Ni}$ and Co base superalloys. In particular CoNiCrAlY alloy provides protection against high temperature oxidation, while CoNiCrAlY alloy provides excellent protection against molten salt corrosion. Due to the combination of $\mathrm{Ni}+\mathrm{Co}$ the MCrAlY system its now widely used as an option for application that require protection against oxidation at high temperatures (hot corrosion), and where the thermal insulation it's not a primary requirement [5].

The aluminum effect at a MCrAlY system it's to provide an oxide layer that can be regenerated constantly to prevent the aggressive attack of chemical species, such as $\mathrm{Cl}$ - and sulfides, which can be harmful to the coating and the base metal, while chromium helps stability of total oxide layer to maintain its protective features. However, excessive content of $\mathrm{Cr}$ affects 
the stability. Finally, yttrium helps maintain adherence of the oxide layer on the surface of the substrate [5].

Some authors report that oxidation at $1000^{\circ} \mathrm{C}$ of coatings deposited by HVOF MCrAlY is significantly influenced by the density of the coating, since defect sand pores are pathways that promote the diffusion of ions [6]. Moreover, other authors suggest that a higher roughness of the coating may result in higher oxidation because most surfaces are exposed to the atmosphere [7]. However, the authors concluded that the surface roughness has no significant influence on the oxidation process [6].

Lugscheider et al. [4] presented one of the first works with MCrAlY system where different sets of system operating parameters for HVOF optimized thicknesses and properties in these films. These parameters were the $\mathrm{H} / \mathrm{O}$, the working distance, the rate of powder feed, and the type of carrier gas [4]. The authors mention that a key point to obtain films with low oxygen content is to prevent complete melting of the particles and achieve high processing speeds. Allowing higher speeds spray particles has been projected on a plastic rather than in a molten state, which hallows to preserve the microstructure of the coating powder [3].

Lugscheider et al. [4] found that small changes in the particle size can significantly change the heat contented velocity of the particles thus altering their ability to deform plastically. Regarding the working distance Voggenreiter et al. [8] found that an increase in that variable, from a base of $250 \mathrm{~mm}$ to a maximum of $300 \mathrm{~mm}$, resulted in approximately reduction of one third in the oxygen content of the coating. Zhao and Lugscheider [3] together at this point reported a decrease in the oxygen content of 1.53 to $0.987 \%$ by weight, in a coating produced by $\mathrm{HVOF} \mathrm{NiCoCrAlY}$ when working distance increased from 250 to $300 \mathrm{~mm}$.

Due to the above, the present study evaluated the projection distance as a process variable in thermal spraying HVOF system for coatings with the following characteristics: high adhesion, high density, greater hardness, and low oxide content. Once obtained these features optimized coating that was applied to the first step of a geothermal steam turbine (diaphragm or stator). This coating is intended to diminish the effects of corrosion and erosion in turbine parts suffering, both static and mobile, as currently these components require corrective maintenance period of two years. The user sector will benefit from obtaining a test application procedure and thermal spray coatings (HVOF), as part of preventive maintenance protocol geothermal steam turbines.

\section{Materials and Methods}

For producing coatings based powder was used as MCrAlY alloy, whose characteristics are included in Table 1. The apparent density of the powder was measured following the guidelines of ASTM B212 [9], while the flow rate was measured using ASTM B964 [10]. As a substrate for coatings samples were used with stainless steel AISI/SAE $3045 \times$ $5 \times 0.5 \mathrm{~cm}$, which were cut by water jet using an OMAX 5555 equipment JetMachining Center. For proper cleaning conditions, the samples to be coated were prepared surface
TABLE 1: Features of powder CoNiCrAlY.

\begin{tabular}{lc}
\hline Chemical composition $^{*}$ & $38.5 \% \mathrm{Co}, 32 \% \mathrm{Ni}, 21 \% \mathrm{Cr}, 8 \% \mathrm{Al}$, \\
Granulometry & $0.5 \% \mathrm{Y}$ \\
Apparent density & $-45 /+15 \mu \mathrm{m}(\mathrm{mesh}-325 /+15 \mu \mathrm{m})$ \\
Flow rate & $3.948 \mathrm{~g} / \mathrm{cm}^{3}$ \\
\hline
\end{tabular}

${ }^{*}$ Weight percentage.

TABLE 2: Deposition of powder conditions of CoNiCrAlY by HVOF.

\begin{tabular}{lc}
\hline Spray distance & $203,229,254,279$ y $305 \mathrm{~mm}$ \\
Transversal speed & $1.0 \mathrm{~m} / \mathrm{s}$ \\
Oxygen pressure & $150 \mathrm{psi}$ \\
Propane pressure & $90 \mathrm{psi}$ \\
Air pressure & $100 \mathrm{psi}$ \\
Carrier gas & Nitrogen \\
Carrier gas pressure & $150 \mathrm{psi}$ \\
Powder feed & $38 \mathrm{~g} / \mathrm{min}$ \\
\hline
\end{tabular}

by sandblasting $\left(\mathrm{Al}_{2} \mathrm{O}_{3}\right.$ G-20 grade $)$ at a distance of $0.2 \mathrm{~m}$ air pressure 4 bar to obtain a roughness Ra between 5 and 10 microns, which promote the mechanical bond between the substrate and the projected particles.

The powder deposition conditions CoNiCrAlY regarding pressures and flows are those suggested in the literature [5], so that it has a reference or starting point for the manufacture of the coating. However, in order to establish parameters that allow spray accurately control of the final thickness of the coatings was modified by spray distance for their influence on the properties of the coating. Recommended conditions and modified spray parameters are included in Table 2. Tecnar Accura Spray equipment was used for determining the speed and temperature of the particles during their projection on the surface using a high speed camera and low temperature.

The characterization of the coatings was conducted with a cross-section of the coated samples. The microstructure of powder and coatings was studied using scanning electron microscopy, JEOL JSM-6510LV. Quantitation was performed by particles in the interface coating-substrate, determining amount of oxides, porosity, and unmelted particles present in the coating.

Coating hardness was determined using a microhardness LECO M-400-H1 with a load of 300 gf and taking 12 measurements per sample; these measurements were carried out on the same specimens where microstructural characterization was performed. The wear resistance of the coatings was evaluated by testing Pin-on-Disc tribometer using CSM instruments $18-280$. The tests were performed using a ball counterpart $440 \mathrm{C}$ stainless steel with a diameter of $1.5 \mathrm{~mm}$, a radius of $6 \mathrm{~mm}$, and a load of $7 \mathrm{~N}$ and test distances of 100 , 200,300 , and $400 \mathrm{~m}$ and velocity of $5 \mathrm{~cm} / \mathrm{s}$. The variation of the friction coefficient as a function of testing time and the mass loss as a function of distance are reported. Finally, we evaluated the adhesion strength of the coatings following the guidelines of ASTM C633 [11]. Specimens were machined from 304 stainless steel $2.54 \times 6.35 \mathrm{~cm}$ in diameter and length, 


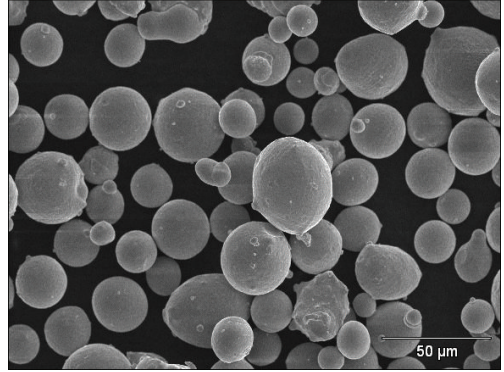

(a)

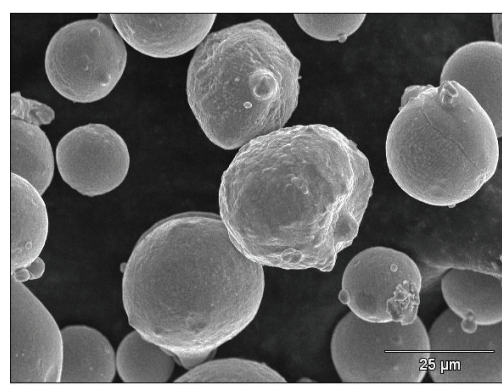

(b)

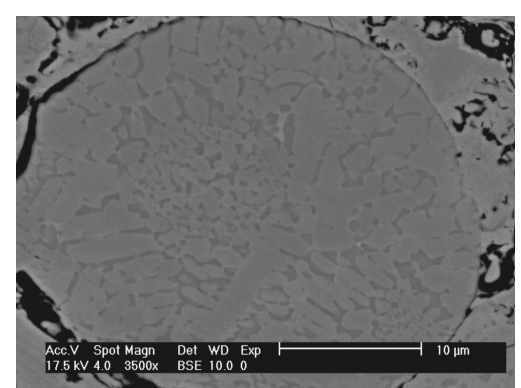

(c)

FIGURE 1: $\mathrm{Co}_{32} \mathrm{Ni}_{21} \mathrm{Cr}_{8} \mathrm{Al}_{0.5} \mathrm{Y}$ powder micrograph by SEM. (a) and (b) morphology and (c) cross-section.

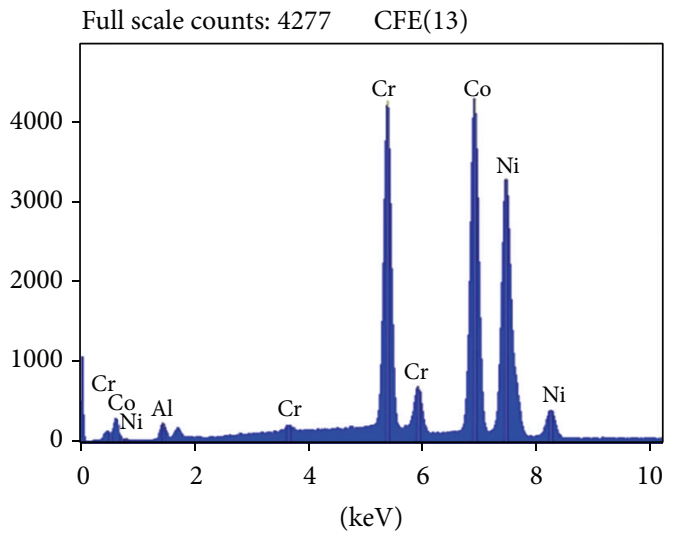

(a)
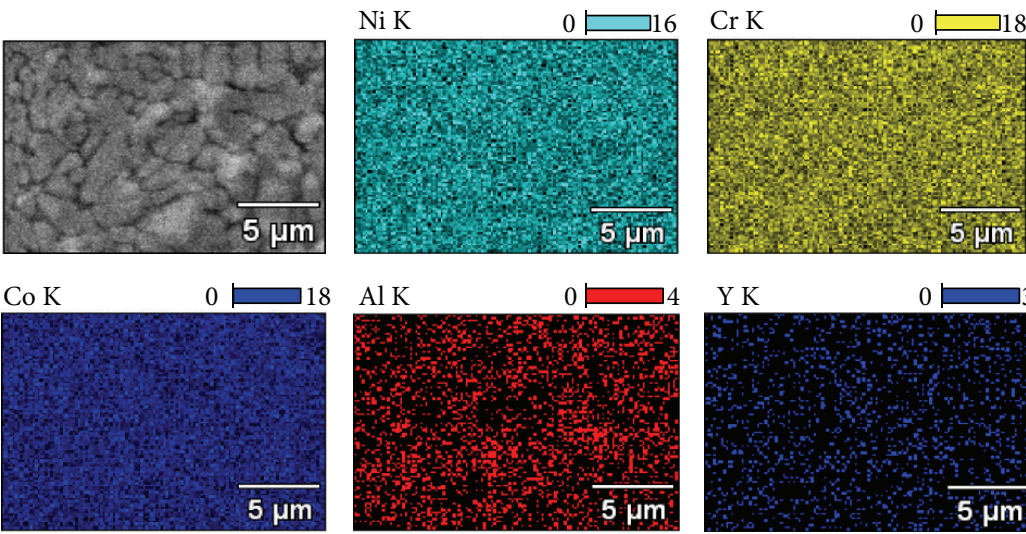

(b)

FIGURE 2: (a) EDS spectrum and (b) EDS elemental mapping of powder particle CoNiCrAlY.

respectively. The end of the sample opposite to the cord is applied to the coating surface preparation study following sandblast mentioned above. Once the coating is applied, the sample is bonded to another uncoated sample by an epoxy adhesive which cures at a temperature of $70^{\circ} \mathrm{C}$ for 90 minutes. Tensile tests were performed on a machine STM Form 10EZ with capacity of 5 tons at a crosshead speed of $1 \mathrm{~mm} / \mathrm{min}$. The maximum load which showed the failure was recorded. Subsequently, the fracture surfaces were observed in the stereoscope to determine where the failure occurred, that is, whether the substrate-coating interface or adhesive coatings interface.

\section{Results and Discussion}

3.1. Morphology and Microstructure of the Powder. The morphology of the powders is shown in Figure 1. The powder morphology is predominantly spherical particles with a few slightly elongated semispherical. The particle surface is smooth in appearance without satellite particles adhered to it. Figure 1(a) shows a micrograph of a sample of dust which shows a predominance of particles with sizes between 30 and 40 microns. There were also smaller particles but to a lesser extent. The microstructure of the powder was also studied in SEM cross-sections. The microstructure consists of columnar and equiaxed grains, without observing a dominant effect on the other structure. In some cases we get to observe dendritic growth in them. In general, the microstructure of the powders confirms that processing occurred by inert gas atomization. This is because structural morphologies characteristic of solidification processes at low speeds are compared with other powders solidification processes, such as spraying with water.

In order to distinguish the distribution of chemical elements in the dust EDS studies were carried on particles. Figure 2(a) shows a characteristic spectrum which shows the presence of chemical elements present in the alloy and the relative percentage thereof. We found a correlation between the composition reported by the supplier of the alloy and the results of the tests performed in this study. An elemental mapping was also performed on dust particles to determine the distribution of $\mathrm{Co}, \mathrm{Ni}, \mathrm{Cr}, \mathrm{Al}$, and $\mathrm{Y}$ in them. Figure 2 shows the results of this mapping in a dust particle and also that the alloying elements are distributed homogeneously and in proportion with the chemical composition; what it means is that aluminum and yttrium are lesser extent but uniformly distributed. No segregation was noted towards certain areas of the powder particles studied. This behavior was observed in both elongated particles such as round, showing no change in the elemental distribution geometry. 


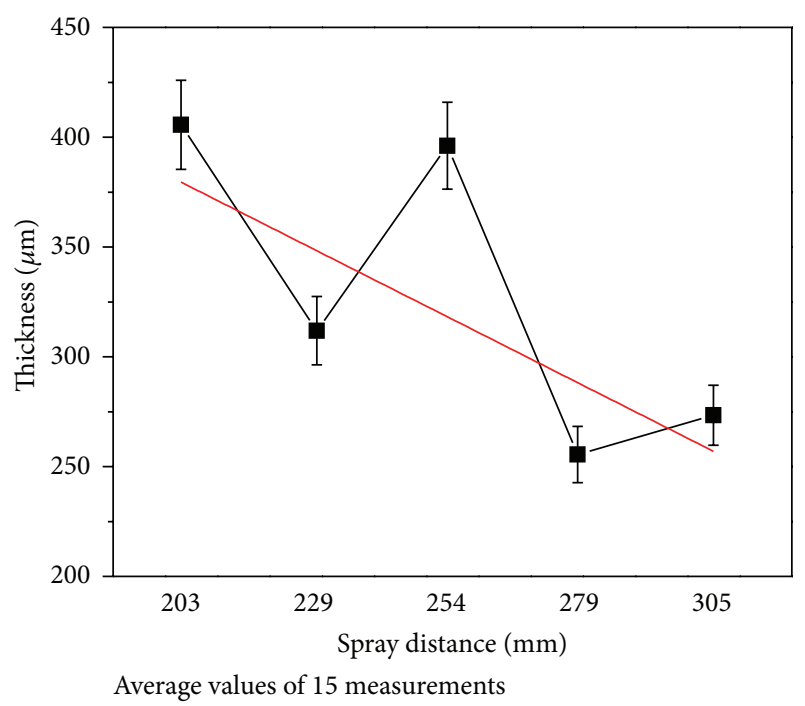

FIGURE 3: $\mathrm{Co}_{32} \mathrm{Ni}_{21} \mathrm{Cr}_{8} \mathrm{Al}_{0.5} \mathrm{Y}$ coating thickness according to the different spray distances.

3.2. Spray Distance. We analyzed five different projection distances: 203, 229, 254, 279, and $305 \mathrm{~mm}$. Figure 3 shows the thickness measured in 304 stainless steel substrates with varying spray distance, the manipulator speed of $1 \mathrm{~m} / \mathrm{s}$, and a total of 6 passes. These results will establish the conditions necessary to control the final thickness of the coating $\mathrm{Co}_{32} \mathrm{Ni}_{21} \mathrm{Cr}_{8} \mathrm{Al}_{0.5} \mathrm{Y}$.

As shown in Figure 3, the coating thickness decreases as distance increases except for the projection sample deposited at $254 \mathrm{~mm}$. This is because as the projection distance is increased, there is a decrease in velocity due to the effects cutting on the outer limits of the flame, which brings that not all particles melt and adhere to the surface. The particles lose velocity when projected along the way, which is why the big and heavy particles have less kinetic energy and they are not melted completely; this causes thicker splats in the flame, less flat, which results in coatings with high percentages of porosity.

3.3. Microstructure. Figure 4 shows the microstructure of the coating section on the substrate at different distances from spray manipulator at a rate of $1 \mathrm{~m} / \mathrm{s}$ and with a total of 6 passes. In general, it is seen that the coating has large amount of dispersed oxide and significant presence of unmelted particles, for example, the most representatives samples are the ones spay at $229 \mathrm{~mm}$ and $254 \mathrm{~mm}$. Similarly, we observed that contaminating particles are present in the substratecoating interface (Figure 4(f)). Also we observed a lot of porosity of different sizes and irregular morphology, as well as interconnected porosity in the particle boundaries.

The quantitative evaluation of the porosity, amount of oxides, unmelted particles (UMP), and the interface contamination was performed using image analysis software "Sigma Scan Pro 5.0." Table 3 presents the results of such analysis whereas in Figure 5 images of how the scan was performed with the software are presented.
TABLE 3: Results of image analysis based on $\mathrm{Co}_{32} \mathrm{Ni}_{21} \mathrm{Cr}_{8} \mathrm{Al}_{0.5} \mathrm{Y}$ coating of different spray distances.

\begin{tabular}{lccccc}
\hline \multirow{2}{*}{ Property } & \multicolumn{5}{c}{ Spray distance (mm) } \\
& 203 & 229 & 254 & 279 & 305 \\
\hline Interface contamination (\%) & 44.1 & 29.8 & 23.9 & 43.0 & 33.8 \\
Oxides (\%) & 3.9 & 3.7 & 2.9 & 6.8 & 7 \\
Porosity (\%) & 2.0 & 0.3 & 0.6 & 4.8 & 4.5 \\
Unmelted particles & 5 & 4 & 4 & 14 & 8 \\
\hline
\end{tabular}

Average values from five image analyses for each case.

As seen in Figure 5, spraying distances of 229 and $254 \mathrm{~mm}$ are where there are the best conditions for applying the coating, since these have the lowest oxide content, porosity, unmelted particles, and contamination at the interface. The spray distance influences the oxide content in coatings applied by HVOF, as mentioned in some work that the oxygen content of NiCoCrAlY coatings is reduced from 1.53 to $0.97 \%$ by weight, increasing the spraying distance from 250 to $300 \mathrm{~mm}[4,5,7]$. However, in this case the oxide content increases by increasing the spraying distance from 254 to $305 \mathrm{~mm}$; this is due to a higher retention of particles in the flame. Note that the distance of $254 \mathrm{~mm}$ spray distance is recommended by the manufacturer of the powders. Through Tecnar Accura Spray equipment speed and temperature of the particles to be projected were determined onto the surface. Figure 6 shows the results obtained by the analysis.

It is evident that in Figure 6, at a greater distance than the projection presents, a higher temperature of the particles is observed; however, the speed decreases considerably. As can be seen, a spray distance of 229 to $254 \mathrm{~mm}$ is that which presents the best combination of speed and temperature of the particles, where its kinetic energy 13 does not decrease at the expense of an increase in the same temperature, which produced the best properties of the coating.

3.4. Microhardness. Coating hardness was determined by microindentation in the cross-section. Different measurements were performed along the studied samples with 12.5 microns separations. Figure 7 shows the results of microhardness of the five spray distances used. The hardness showed values within a range between 400 and $550 \mathrm{HV}$, being lower than those reported in the literature for NiCoCrAlY alloys deposited by HVOF (>1000 HV) [12]. However, the provider of the powders presented in the sheet hardness between 350 and 450 with $300 \mathrm{~g}$ loads [5]. It can be seen that the sample sprayed from a distance of $254 \mathrm{~mm}$ is the one with a higher hardness, followed by the sample that was sprayed at $229 \mathrm{~mm}$.

3.5. Adherence. Adhesion tests were conducted according to ASTM C633 [11]. Figure 8(a) shows the results. It is observed that distances of 229 and $254 \mathrm{~mm}$ have the highest values of adhesion, while at a distance of $203 \mathrm{~mm}$ lower adhesion value is obtained. Some adhesion values reported in the literature for NiCrAlY alloys are in the range of 57 to $70 \mathrm{MPa}$ depending on the chemistry and deposition conditions [1315]. In this work, were obtained adhesion values within such 


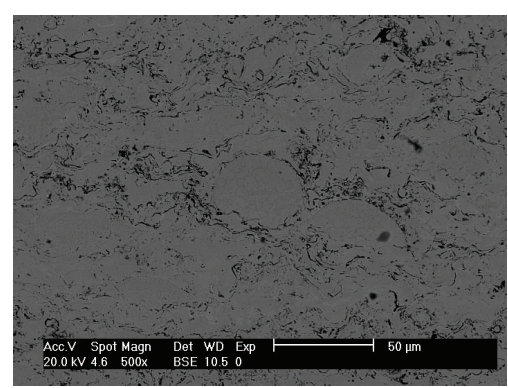

(a)

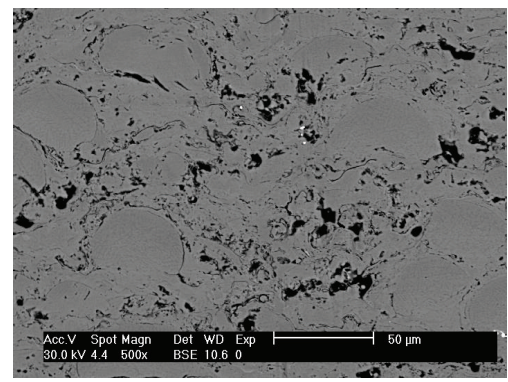

(d)

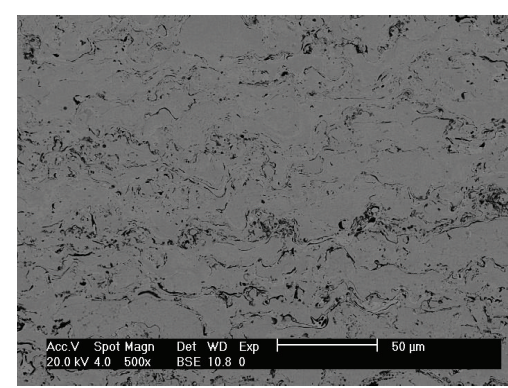

(b)

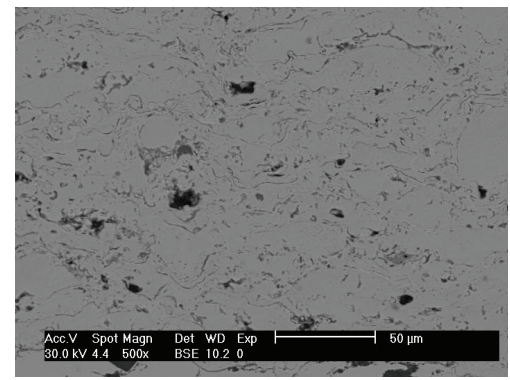

(e)

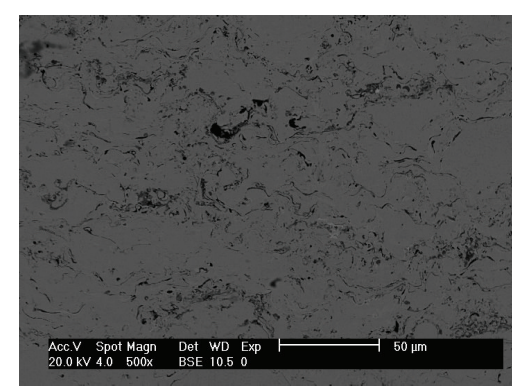

(c)

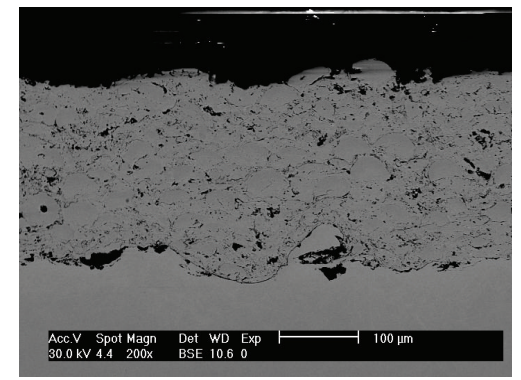

(f)

FIGURE 4: $\mathrm{Co}_{32} \mathrm{Ni}_{21} \mathrm{Cr}_{8} \mathrm{Al}_{0.5} \mathrm{Y}$ coating microstructure of a cross-section of different spray distances: (a) $203 \mathrm{~mm},(\mathrm{~b}) 229 \mathrm{~mm}$, (c) $254 \mathrm{~mm}$, (d) $279 \mathrm{~mm}$, (e) $305 \mathrm{~mm}$, and (f) contaminants particles.

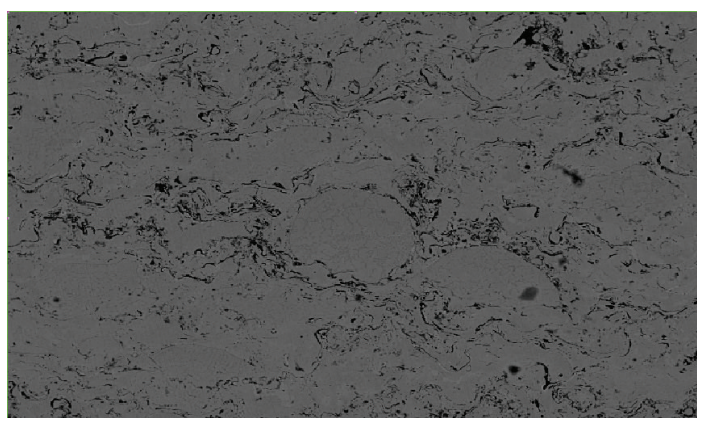

(a)

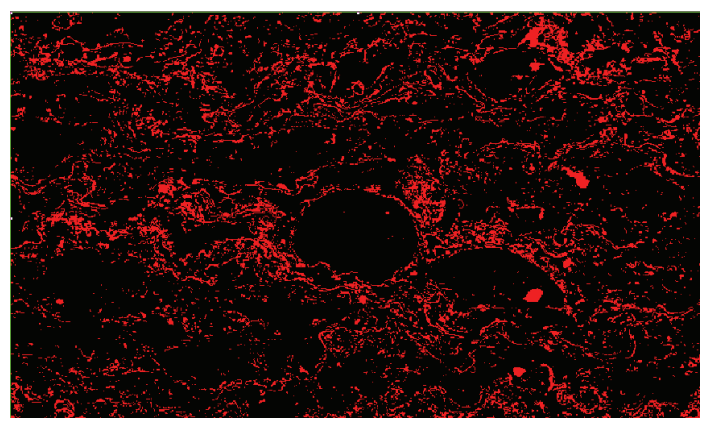

(c)

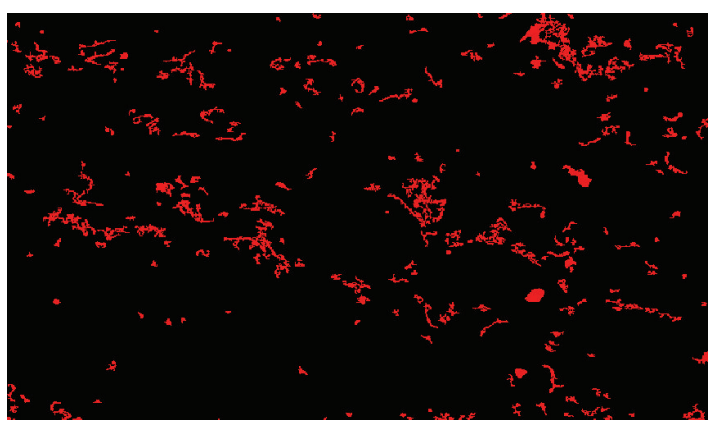

(b)

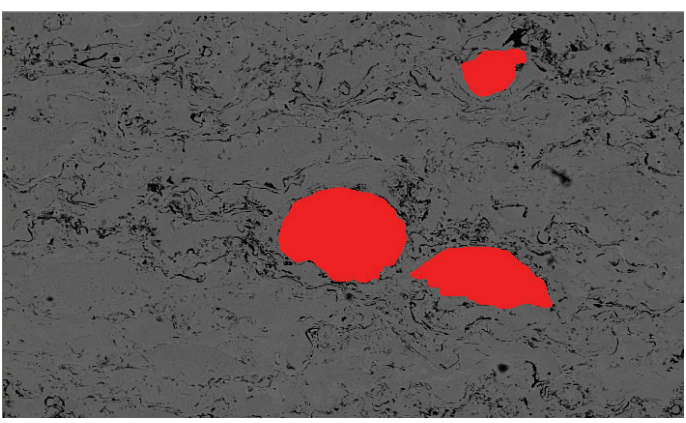

(d)

FIGURE 5: Image analysis of the coatings $\mathrm{Co}_{32} \mathrm{Ni}_{21} \mathrm{Cr}_{8} \mathrm{Al}_{0.5} \mathrm{Y}$, showing (a) original image, (b) content of oxides and pores, (c) porosity, and (d) unmelted particles.

range, except for the samples sprayed at $203 \mathrm{~mm}$, so the spray distance is an important parameter to be considered for tuning the processing conditions and thus to maintain or even improve the adhesion of the coatings. Additionally, adhesion tests were performed with different tilt, to observe how this parameter affects the adhesion of the coatings. For this test the distance was $254 \mathrm{~mm}$ because it shows the best properties in the above tests carried out in this work. 


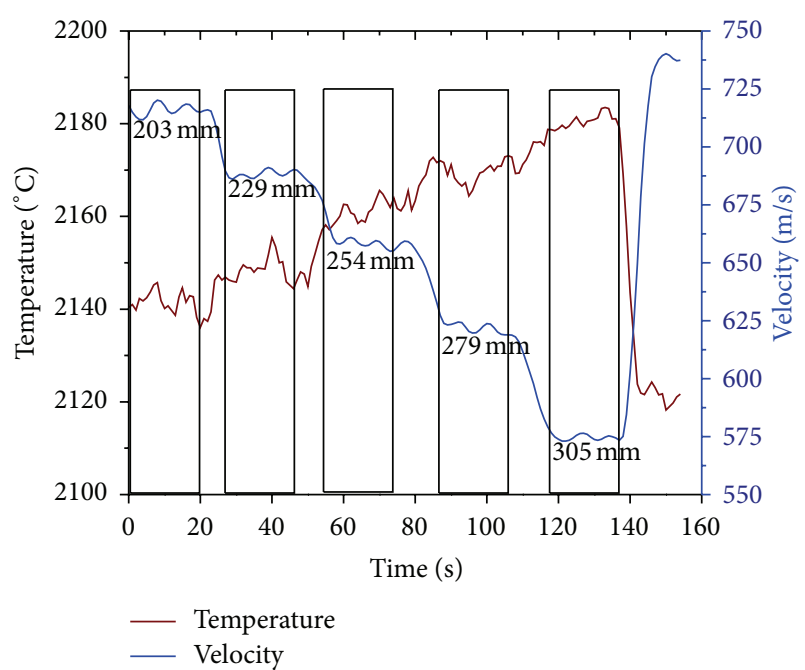

FIGURE 6: Results of speed and temperature of the particles with the Tecnar Accura Spray equipment.

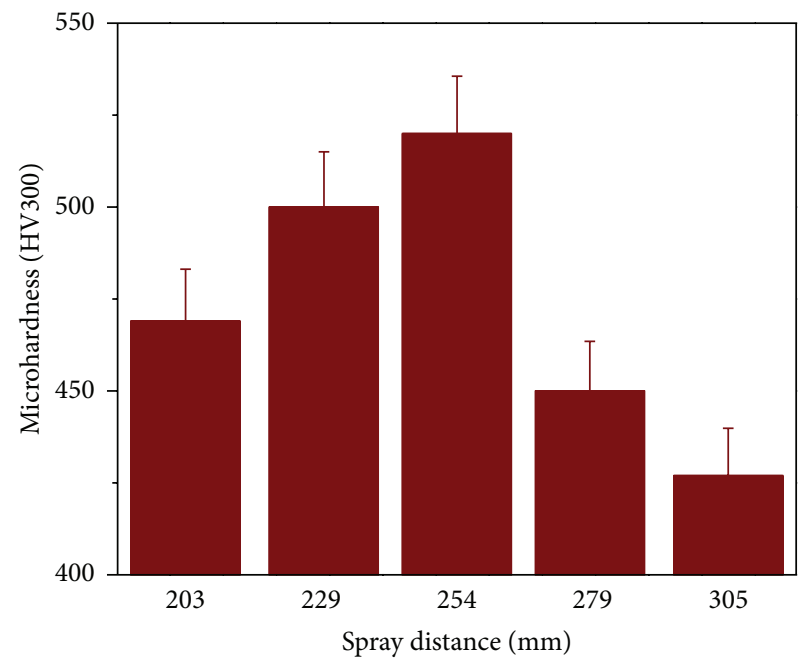

Figure 7: Microhardness $\mathrm{Co}_{32} \mathrm{Ni}_{21} \mathrm{Cr}_{8} \mathrm{Al}_{0.5} \mathrm{Y}$ coating to different spray distances employed.

In general it was found that the adhesion force decreases as the angle of incidence of the projection decreases, taking a greater adhesion force when the projection is performed $90^{\circ}$ from the direction of the flame (Figure $8(\mathrm{~b})$ ). Generally, in testing adhesion failure occurred in the substrate-coating interface, so the tests are considered valid; this can be seen in Figure 9.

3.6. Wear Resistance. For this purpose, the friction coefficient was obtained at a distance of $100 \mathrm{~m}$ and the mass loss at the distances 100, 200, 300, and $400 \mathrm{~m}$. Figure 10 shows the results of the friction coefficient. As shown in Figure 10, the spray distance is a parameter that significantly affects the wear resistance of the coatings; it is not appreciably decreased as the friction coefficient is varied according to spraying distance. Furthermore, there are some significant

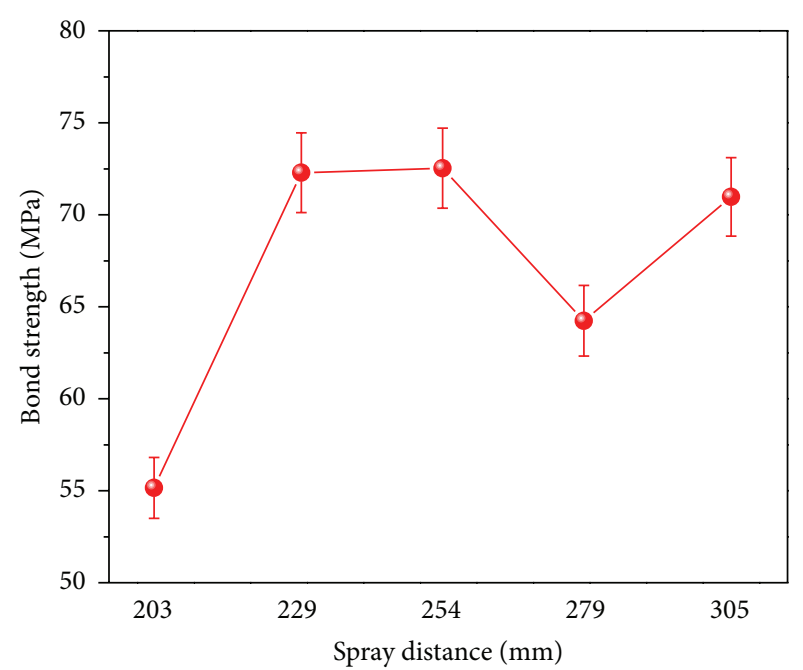

(a)

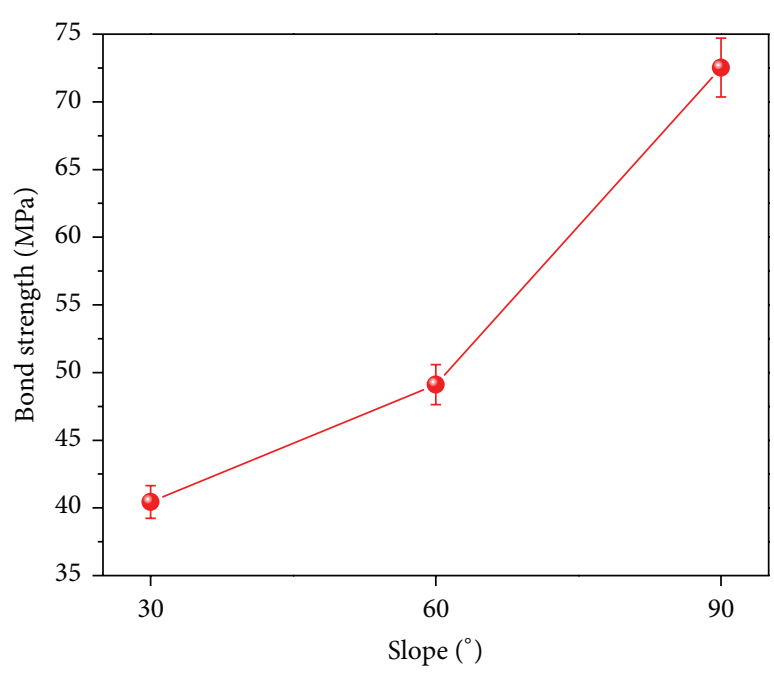

(b)

FIGURE 8: Bond strength $\mathrm{Co}_{32} \mathrm{Ni}_{21} \mathrm{Cr}_{8} \mathrm{Al}_{0.5} \mathrm{Y}$ coatings. (a) Depending on the spray distance and (b) depending on the inclination.

fluctuations in the friction coefficient, which are attributable to delamination of agglomerations of particles which wear on the friction surface [12]. Mass loss test at distances of 100, 200,300 , and $400 \mathrm{~m}$, for spraying distances of 203,254 , and $305 \mathrm{~mm}$, is shown in Figure 11. It is evident that the coatings have an increased mass loss test as the distance increases. This behavior of the coated samples is that the particles are partially joined and tend to be detached, which makes the coating susceptible to wear in addition this effect is more pronounced as the distance increases test.

\section{Conclusions}

(i) The spray distance is a parameter that significantly affects the mechanical properties of the coatings $\mathrm{Co}_{32} \mathrm{Ni}_{21} \mathrm{Cr}_{8} \mathrm{Al}_{0.5} \mathrm{Y}$ by HVOF spraying system. 


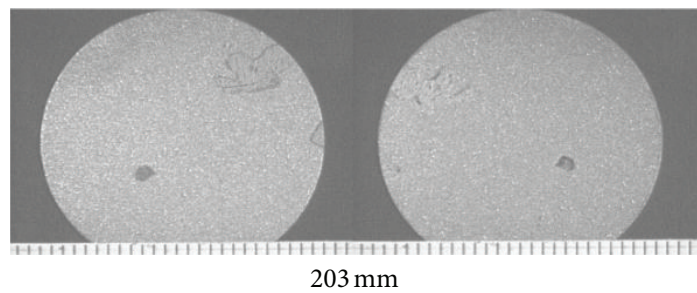

(a)

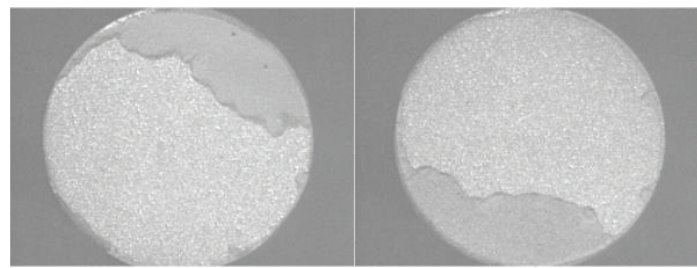

$254 \mathrm{~mm}$

(c)

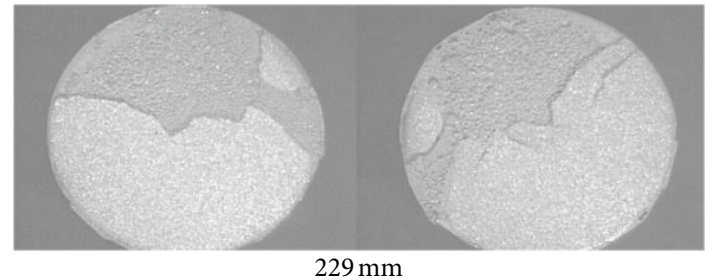

(b)

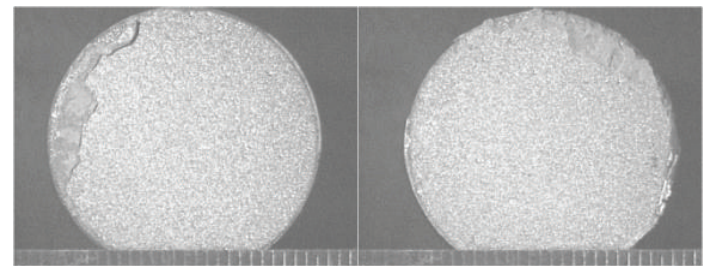

$305 \mathrm{~mm}$

(d)

FIGURE 9: Specimens after the adhesion test.

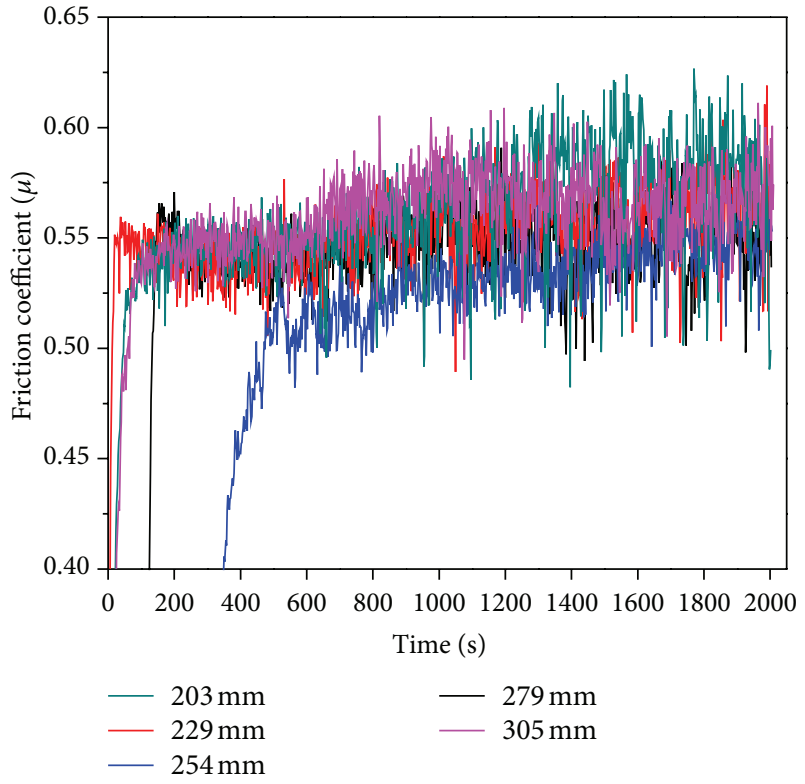

Figure 10: Coefficient of friction results in a distance of $100 \mathrm{~m}$.

(ii) Best CoNiCrAlY coating properties were obtained at spray distance of 229 to $254 \mathrm{~mm}$ (8 and 9 in), since these distances are obtained at the lowest values of oxides, porosity, contamination at the interface, and unmelted particles, while the hardness showed the highest values at these distances.

(iii) The coating thickness tends to decrease with increasing the projection distance, largely due to the fact that some particles do not melt and therefore do not adhere to the surface.

(iv) It was determined that the temperature of the particles traveling in the flame increases as the spraying

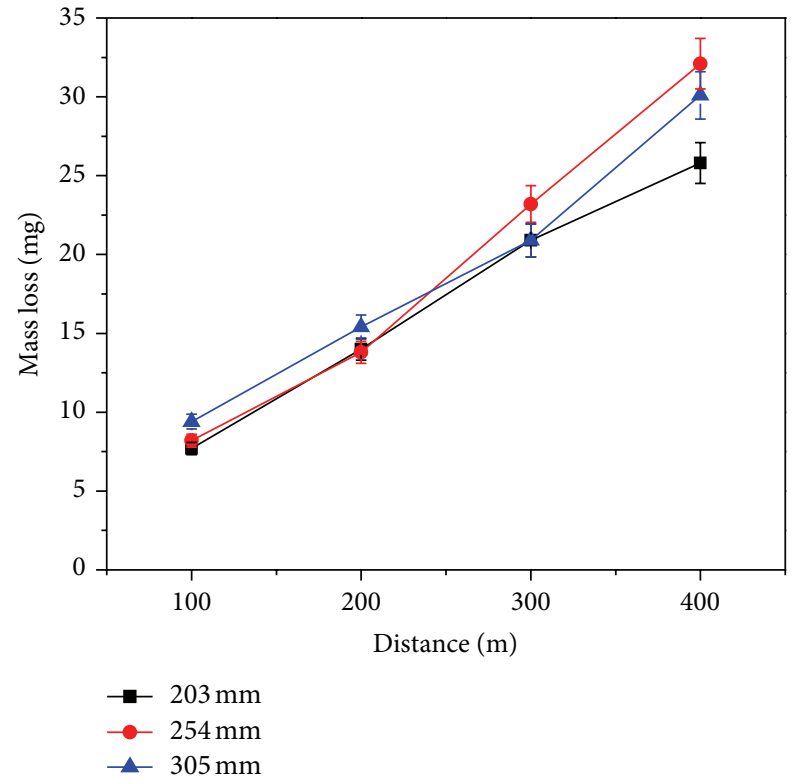

FIGURE 11: Mass loss for spraying distances of 203, 254, and $305 \mathrm{~mm}$ $\mathrm{Co}_{32} \mathrm{Ni}_{21} \mathrm{Cr}_{8} \mathrm{Al}_{0.5} \mathrm{Y}$ coatings.

distance increases, while the speed of the particles is observed to have the opposite effect. There is a decrease in speed as the spraying distance increases.

(v) The higher adhesive strength occurs at distances of 229 and $254 \mathrm{~mm}$. The inclination is an important factor in adhesion strength of the coatings; noting a decrease in this angle decreases application.

(vi) The spray distance is a parameter that significantly affects the wear resistance of the coatings; it is not appreciably decreased as friction coefficient is varied according to spray distance. 


\section{Conflict of Interests}

The authors declare that there is no conflict of interests regarding the publication of this paper.

\section{Acknowledgments}

The authors acknowledge the sectorial fund for research and technological development in energy CFE-CONACYT (Project no. 120653), work group UANL-A-316, and the Centro de Tecnología Avanzada for allowing the use of their facilities.

\section{References}

[1] A. M. Khoddami, A. Sabour, and S. M. M. Hadavi, "Microstructure formation in thermally-sprayed duplex and functionally graded NiCrAlY/Yttria-stabilized Zirconia coatings," Surface and Coatings Technology, vol. 201, no. 12, pp. 6019-6024, 2007.

[2] C. R. C. Lima and J. M. Guilemany, "Adhesion improvements of thermal barrier coatings with HVOF thermally sprayed bond coats," Surface and Coatings Technology, vol. 201, no. 8, pp. 4694-4701, 2007.

[3] L. Zhao and E. Lugscheider, "High velocity oxy-fuel spraying of a NiCoCrAlY and an intermetallic NiAl-TaCr alloy," Surface and Coatings Technology, vol. 149, no. 2-3, pp. 231-235, 2002.

[4] E. Lugscheider, C. Herbst, and L. Zhao, "Parameter studies on high-velocity oxy-fuel spraying of MCrAlY coatings," Surface and Coatings Technology, vol. 108-109, no. 1-3, pp. 16-23, 1998.

[5] AMDRY 995 Thermal Sprayed MCrAlY Powders Technical Bulletin \#10-648.

[6] S. Serghini and S. Dallaire, "Cyclic and isothermal oxidation at $1200^{\circ} \mathrm{C}$ of HVOF NiCrAlY sprayed coatings," in Proceedings of the 1st International Thermal Spray Conference on Thermal Spray Surface Engineering via Applied Research, pp. 1005-1009, May 2000.

[7] L. Zhao, M. Parco, and E. Lugscheider, "High velocity oxy-fuel thermal spraying of a NiCoCrAlY alloy," Surface and Coatings Technology, vol. 179, no. 2-3, pp. 272-278, 2004.

[8] H. Voggenreiter, H. Huber, S. Beyer, and H.-J. Spies, "Influence of particle velocity and molten phase on the chemical and mechanical properties of HVOF-sprayed structural coatings of Alloy 316L," in Advances in Thermal Spray Science and Technology, C. C. Berndt and S. Sampath, Eds., pp. 303-308, ASM International, Materials Park, Ohio, USA, 1998.

[9] ASTM B212-09, "Standard test method for apparent density of free-flowing metal powders using the hall flowmeter funnel," 2008.

[10] ASTM B964-09, "Standard test methods for flow rate of metal powders using the carney funnel," 2008.

[11] ASTM C663 international, "Standard test method adhesion or cohesion strength of thermal spray coatings," 2008.

[12] L. Zhao, M. Parco, and E. Lugscheider, "Wear behaviour of $\mathrm{Al}_{2} \mathrm{O}_{3}$ dispersion strengthened MCrAlY coating," Surface and Coatings Technology, vol. 184, no. 2-3, pp. 298-306, 2004.

[13] R. A. Mahesh, R. Jayaganthan, and S. Prakash, "Microstructural characteristics and mechanical properties of HVOF sprayed NiCrAl coating on superalloys," Journal of Alloys and Compounds, vol. 468, no. 1-2, pp. 392-405, 2009.
[14] C. Zhang, H. Liao, C. Coddet, C. Malavolta, B. Hansz, and S. Keller, "Characterization of coatings sprayed with AMT200 HVOF system," 2011, http://www.confex.com/.

[15] "Flame Spray Technologies, SprayTech, document 06MA.PO .130," September 2000. 

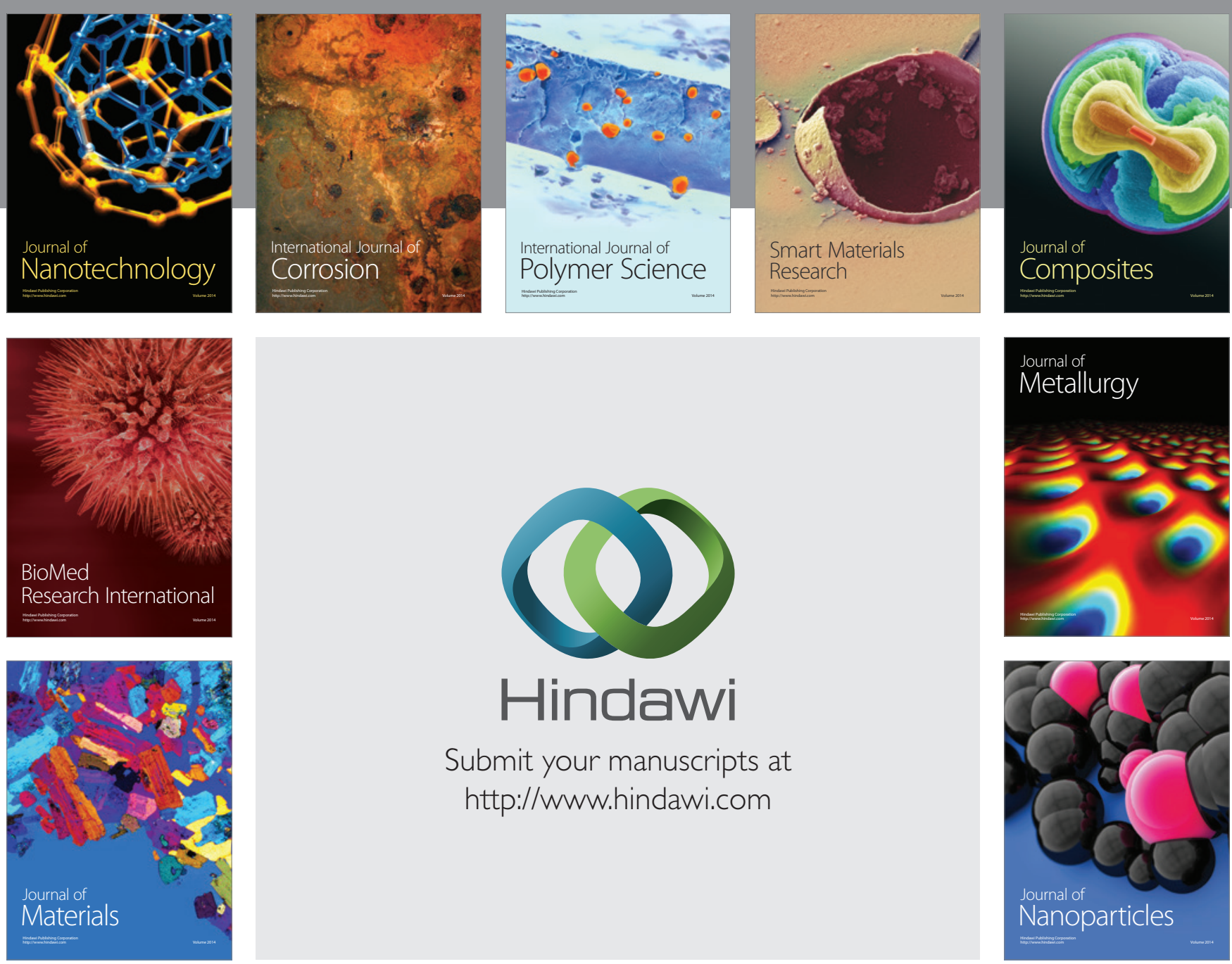

Submit your manuscripts at http://www.hindawi.com
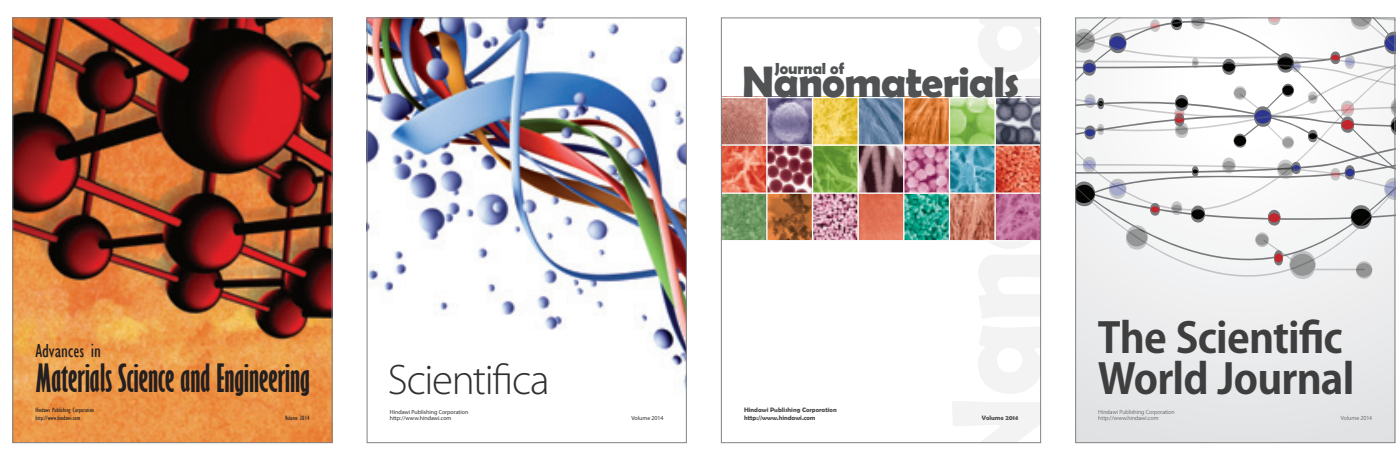

\section{The Scientific World Journal}
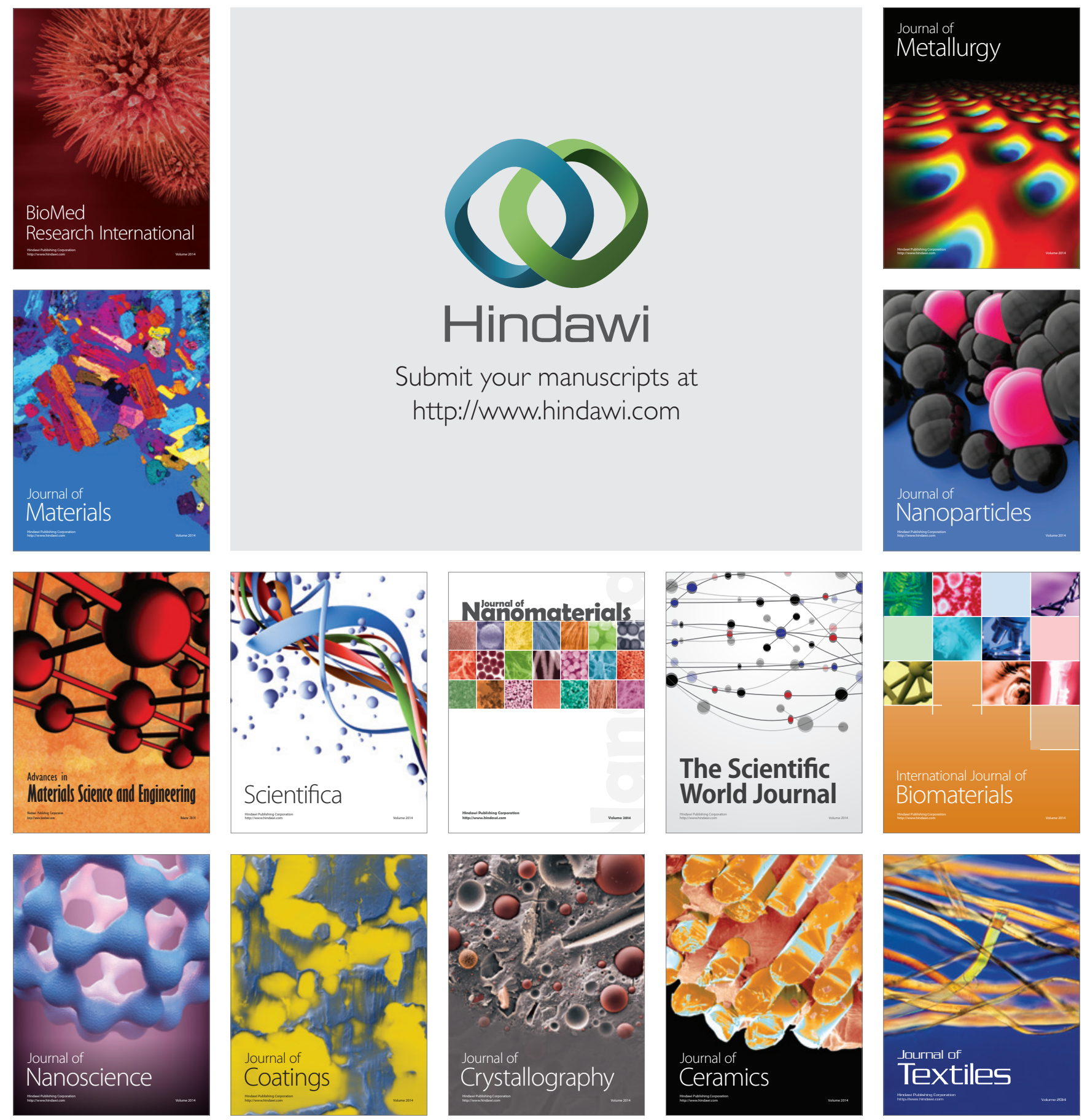